\title{
A multicentre study of the prevalence of diabetic peripheral neuropathy in the United Kingdom hospital clinic population
}

\author{
M.J. Young ${ }^{1}$, A.J.M. Boulton ${ }^{1}$, A.F.Macleod ${ }^{2}$, D. R. R. Williams ${ }^{3}$ and P.H.Sonksen ${ }^{2}$ \\ 'University Department of Medicine, Manchester Royal Infirmary, Oxford Road, Manchester, \\ ${ }^{2}$ Department of Endocrinology and Chemical Pathology, St. Thomas' Hospital, London, and \\ ${ }^{3}$ Department of Community Medicine, Addenbrookes Hospital, Cambridge, UK
}

\begin{abstract}
Summary. A cross-sectional multicentre study of randomly selected diabetic patients was performed using a standardised questionnaire and examination, to establish the prevalence of peripheral neuropathy in patients attending 118 hospital diabetes clinics in the UK. Vibration perception threshold was performed in two centres to compare with the clinical scoring systems. A total of 6487 diabetic patients were studied, $53.9 \%$ male, median age 59 years (range 18 90 years), $37.4 \%$ Type 1 (insulin-dependent) diabetes mellitus, with a median duration of diabetes 8 years $(0-62$ years). The overall prevalence of neuropathy was $28.5 \%$ (27.4 $29.6 \%$ ) (95\% confidence interval) in this population. The prevalence in Type 1 diabetic patients was $22.7 \%$ (21.0$24.4 \%$ ) and in Type 2 (non-insulin-dependent) diabetic patients it was $32.1 \%(30.6-33.6 \%)$. The prevalence of diabetic peripheral neuropathy increased with age, from $5 \%$ (3.1$6.9 \%)$ in the $20-29$ year age group to $44.2 \%(41.1-47.3 \%)$ in the 70-79 year age group. Neuropathy was associated with
\end{abstract}

duration of diabetes, and was present in $20.8 \%(19.1-22.5 \%)$ of patients with diabetes duration less than 5 years and in $36.8 \%(34.9-38.7 \%)$ of those with diabetes duration greater than 10 years. Mean vibration perception threshold measured at the great toe was $21.1 \pm 13.5 \mathrm{SD}$ volts and correlated with the neuropathy disability score, $r=0.8 p<0.001$. In conclusion, diabetic peripheral neuropathy is a common complication associated with diabetes. It increases with both age and duration of diabetes, until it is present in more than $50 \%$ of Type 2 diabetic patients aged over 60 years. An increased awareness of the high prevalence of peripheral neuropathy, especially in older patients, should result in improved screening programmes in order to reduce the high incidence of neuropathic diabetic foot ulceration.

Key words: Diabetes Mellitus, peripheral neuropathy, epidemiology.
Estimates of the prevalence of diabetic peripheral neuropathy vary widely in the literature [1-11]. This apparant diversity is due to the relatively small size of these studies, to differences in the diagnostic criteria employed and to the different methods of patient selection. Whilst some authors have considered painful symptoms alone to be diagnostic [1], others have required signs of nerve dysfunction [2]. Dyck et al. [12] proposed that two of the following three criteria should be present for a diagnosis of peripheral neuropathy: signs of peripheral neuropathy, abnormalities of quantitative sensory testing or abnormal electrophysiological tests. Routine out-patient practice and mass screening requirements have led to the development of simpler scoring techniques for both symptoms [3, 13-15] and signs $[4,16]$. The present survey used standardised questionnaires and examinations, based on these scoring systems. The aim of this study was to estimate the prevalence of peripheral neuropathy in the UK hospital clinic population and, by surveying a large number of patients, to study the relationship of prevalence to age and duration of diabetes.

\section{Subjects and methods}

One hundred and eighteen hospital diabetes clinics in the UK participated in the study. Each was requested to examine a total of 60 diabetic patients, attending routine clinic visits. Those centres with a register randomly selected 20 patients from each of three diabetes duration groups: less than 5 years, 5-10 years and more than 10 years. In those centres without a register patients were examined on a sample basis, usually every fourth or fifth patient, according to the size of the clinic. The data were collected simultaneously in all centres over a 2-month period. Demographic data and history of diabetes were recorded. Patients were designated as Type 2 (non-insulin-dependent) diabetic if they were not currently treated with insulin or were not started on insulin within 2 years after diagnosis. The characteristics of the patients examined are detailed in Table 1 . The neuropathy disability score and neuropathy symptom score for each patient was derived as described in the following.

Neuropathy disability score (NDS): this was derived from examination of the ankle reflex, vibration, pin-prick and temperature (cold tuning fork) sensation at the great toe. The sensory modalities were scored as either present $=0$ or reduced/absent $=1$ for each side, and reflexes as normal $=0$, present with reinforcement $=1$ or $a b$ sent $=2$ per side. Thus the total maximum abnormal score was 10 . A 
Table 1. Patient characteristics

\begin{tabular}{lllll}
\hline & $\begin{array}{l}\text { Total } \\
\text { number } \\
\text { of patients }\end{array}$ & $\begin{array}{l}\text { Male pa- } \\
\text { tients } \\
(\%)\end{array}$ & $\begin{array}{l}\text { Median age } \\
\text { (range) }\end{array}$ & $\begin{array}{l}\text { Median } \\
\text { duration } \\
\text { of diabetes } \\
\text { (range) }\end{array}$ \\
\hline $\begin{array}{lllll}\text { Type 1 } \\
\text { diabetes }\end{array}$ & 2414 & $\begin{array}{l}1298 \\
(53.7 \%)\end{array}$ & $\begin{array}{l}45 \\
(18-90) \text { years }\end{array}$ & $\begin{array}{l}13 \\
(0-62) \text { years }\end{array}$ \\
$\begin{array}{l}\text { Type 2 } \\
\text { diabetes }\end{array}$ & 3949 & $\begin{array}{l}2129 \\
(53.9 \%)\end{array}$ & $\begin{array}{l}63 \\
(19-90) \text { years }\end{array}$ & 6 \\
$(0-55)$ years \\
Unknown & 124 & $\begin{array}{l}71 \\
(57.2 \%)\end{array}$ & & \\
Total & 6487 & 3498 & 59 & 8 \\
& & $(53.9 \%)$ & $(18-90)$ years & $(0-62)$ years \\
\hline
\end{tabular}

Table 2. Diabetic neuropathy by region

\begin{tabular}{llll}
\hline Region & $\begin{array}{l}\text { Total number } \\
\text { of patients }\end{array}$ & $\begin{array}{l}\text { Prevalence of dia- } \\
\text { betic neuropathy }\end{array}$ & $\begin{array}{l}\text { Confidence } \\
\text { intervals }\end{array}$ \\
\hline Scotland & 577 & 23.2 & $19.7-26.6$ \\
Yorkshire & 562 & 31.3 & $27.5-35.1$ \\
N W Thames & 538 & 23.4 & $19.8-27.0$ \\
N Western & 508 & 28.3 & $24.4-32.2$ \\
Wales & 497 & 26.2 & $22.3-30.1$ \\
Wessex & 493 & 27.8 & $23.8-31.8$ \\
W Midlands & 465 & 31.0 & $26.8-35.2$ \\
Trent & 449 & 32.1 & $27.8-36.4$ \\
S E Thames & 418 & 33.7 & $29.2-38.2$ \\
Northern & 379 & 34.6 & $29.8-39.9$ \\
N E Thames & 285 & 24.2 & $19.2-29.2$ \\
Oxford & 277 & 34.3 & $28.7-39.9$ \\
S Western & 220 & 30.0 & $23.9-36.0$ \\
Mersey & 210 & 32.9 & $26.5-39.2$ \\
Ireland & 184 & 22.3 & $16.3-28.3$ \\
S W Thames & 181 & 27.0 & $26.5-39.2$ \\
E Anglian & 152 & 21.7 & $15.1-28.2$ \\
\hline
\end{tabular}

score of 3-5 was regarded as evidence of mild neuropathic signs, 6 8 as moderate and a score of 9 or 10 as severe signs of neuropathy.

Neuropathy symptom score (NSS): patients were asked about their experience of pain or discomfort in the legs: if the patient described burning, numbness or tingling a score of 2 was assigned; fatigue, cramping or aching scored 1 . The presence of symptoms in the feet was assigned a score of 2 , the calves 1 and elsewhere a score of 0 . Nocturnal exacerbation of symptoms scored 2 vs 1 for both day and night and 0 for daytime alone. A score of 1 was added if the symptoms had ever woken the patient from sleep. The patients were asked if any manoeuvre could reduce the symptoms: walking was assigned a score of 2 , standing was 1 and sitting or lying down was 0 . The maximum symptom score was 9. A symptom score of 3-4 was taken to imply mild symptoms, 5-6 moderate symptoms and 79 severe symptoms.

The minimum acceptable criteria for a diagnosis of peripheral neuropathy were: moderate signs with or without symptoms, or mild signs with moderate symptoms. Mild signs alone or with mild symptoms were not considered adequate to make a diagnosis of peripheral neuropathy.

In two centres (Manchester and St. Thomas') vibration perception threshold (Biothesiometer, Biomedical, Newbury, Ohio, USA) was measured at the great toe at the same time as the neuropathy disability score was derived. The Biothesiometer was balanced vertically on the pulp of the great toe to measure vibration perception and a mean of three readings was used to derive the value for each patient. A total of 98 patients were tested in this way in order to compare the clinical scoring systems with a standard test of neuropathy. All the Biothesiometers used in this study had been recently calibrated and tested for electrical safety.
Statistical analysis

Results were analysed using SAS Software (SAS Institute Inc, Cary, N.C., USA). Binomial proportions and confidence intervals were used to describe point and interval estimates of prevalence rates. The chi-squared test was used to compare crude prevalence rates between groups. Logistic regression was used to investigate independently significant factors for the presence of neuropathy. Correlation coefficients were calculated for age and duration of diabetes against prevalence of neuropathy in age/duration bands. Correlation coefficients were also calculated between the neuropathy disability and neuropathy symptom scores and vibration perception threshold.

\section{Results}

\section{Prevalence data}

The overall prevalence of diabetic peripheral neuropathy in this population was $28.5 \%(27.4-29.6 \%)$ (95\% confidence intervals) and was similar in both male and female patients, $28.5 \%(27.0-30.0 \%)$ vs $28.5 \%(26.9-30.1 \%)$. There was no significant difference between University teaching hospital patients $(29.4 \%[27.2-31.6 \%])$ and district general hospital patients $(28.3 \%$ [27.0-29.6\%]) and no significant geographical trends were observed (Table 2). Type 2 diabetic patients had a higher overall prevalence of peripheral neuropathy than Type 1 diabetic patients, $32.1 \%(30.6-33.6 \%)$ and $22.7 \%(21.0-24.4 \%)$ respectively $(p<0.001)$, and this was reflected regardless of duration of diabetes (Fig. 1).

Diabetic peripheral neuropathy was also more prevalent with increasing duration of diabetes, from $20.8 \%$ $(19.1-22.5 \%)$ in 2199 patients with diabetes duration of less than 5 years from diagnosis to $36.8 \%(34.9-38.7 \%)$ in 2532 patients with diabetes for more than 10 years (prevalence of peripheral neuropathy vs duration of diabetes $r=0.18 p<0.001$ ).

The prevalence of diabetic neuropathy increased with age from $5.0 \%(3.1-6.9 \%)$ in those patients aged $20-29$ (502 patients), to $44.2 \%(41.1-47.3 \%)$ in those aged 70 79 (1012 patients) (Fig. 2). A correlation of $r=0.994$ $p<0.001$ was found between age and prevalence of neuropathy.

\section{Logistic regression}

A multiple logistic regression analysis of the prevalence of neuropathy was performed, using sex, age, type of diabetes and duration of diabetes as its predictors (Table 3). This confirmed that there was no difference in the prevalence of neuropathy between males and females. Age and duration of diabetes were significant independent predictors of prevalence (both $p<0.001$ ). After correcting for age and duration differences, the excess of neuropathy in Type 2 diabetic patients persisted, with an odds ratio of 1.09 , although this did not reach statistical significance. 


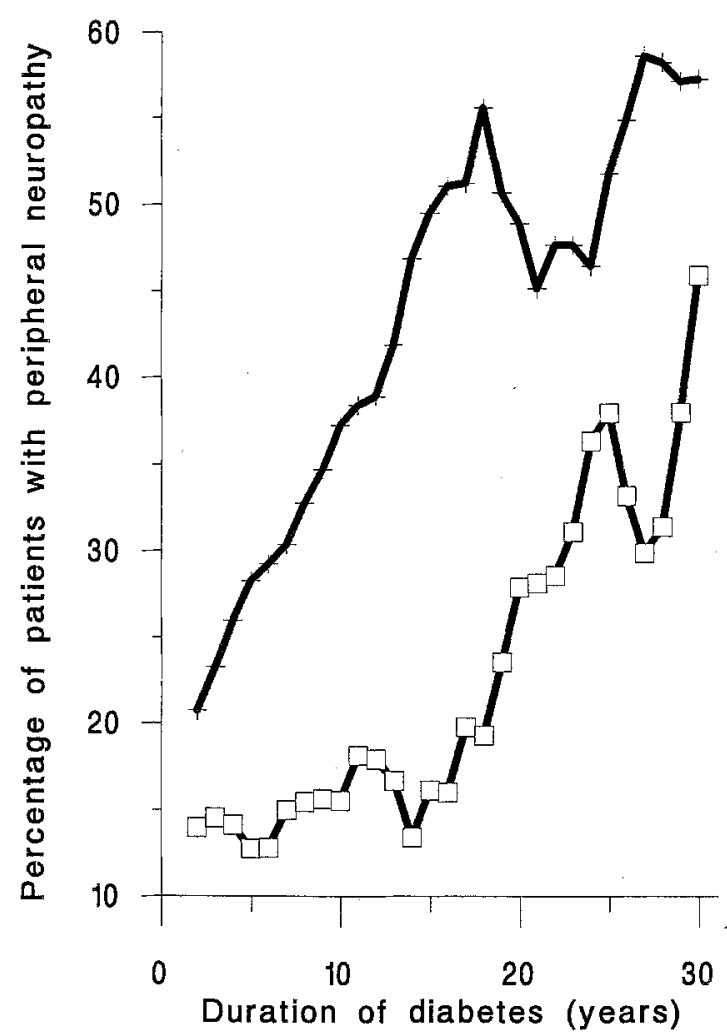

Fig. 1. The prevalence of peripheral neuropathy in Type $1(\square)$ and Type $2(+)$ diabetic patients by duration of diabetes

\section{Vibration perception}

The mean vibration perception threshold at the great toe was $21.1 \pm 13.4 \mathrm{SD}$ volts. A significant correlation was found between the mean vibration perception threshold of both toes and the neuropathy disability score, $r=0.798$ $p<0.001$. A weaker but significant correlation was found between vibration perception and the neuropathy symptom score, $r=0.225 p=0.026$.

\section{Discussion}

The wide variation in the reported rates of diabetic peripheral neuropathy can be explained on the basis of the different diagnostic criteria employed and study populations involved [1-11].

The diagnosis of peripheral sensorimotor neuropathy may be made on the basis of symptoms [3,14, 15], signs $[4,16]$, quantitative sensory tests [17-19] or electrodiagnostic studies [20]. The consensus statement of the San Antonio conference on peripheral neuropathy recommended that an abnormality of one measure in each of these categories should be present for a diagnosis [20], which is clearly more practical in a research than in a routine clinical setting. Dyck et al. [12] proposed that abnormalities in two of three criteria were sufficient to diagnose peripheral sensorimotor neuropathy. The suggested criteria were signs of peripheral neuropathy, quantitative sensory testing and electrophysiological tests. However, because electrophysiological tests are not routinely

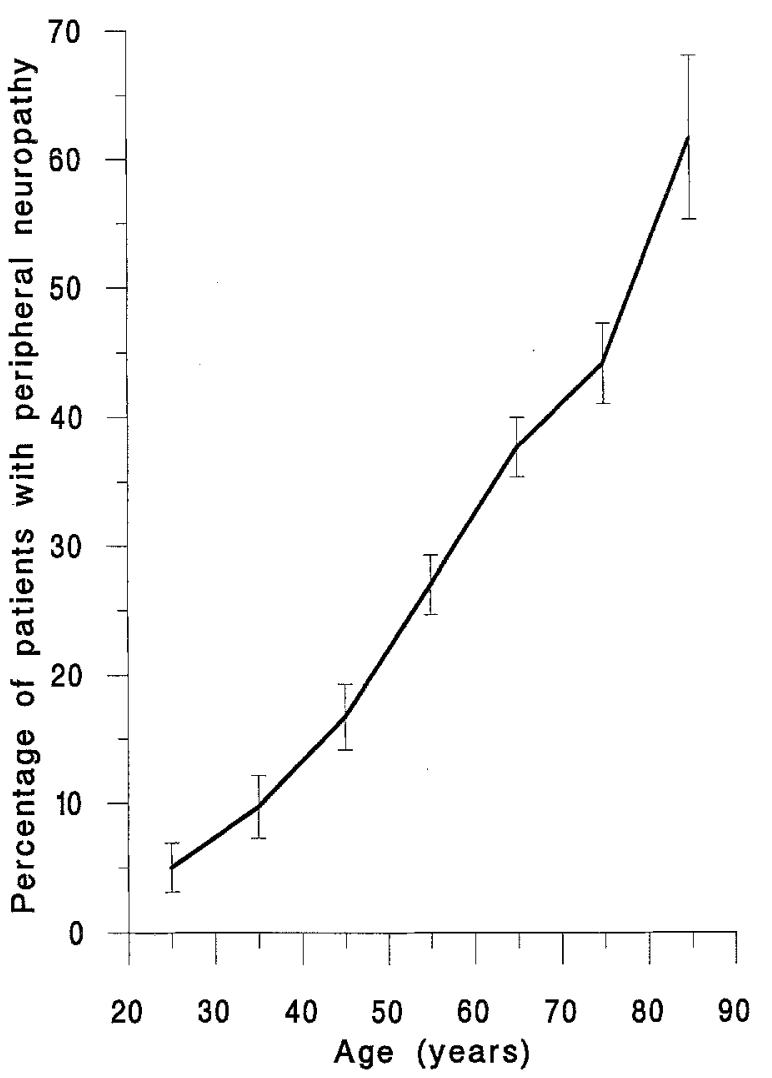

Fig. 2. The prevalence of diabetic peripheral neuropathy by age

available in all centres, these criteria are not in use in everyday clinical practice. The neuropathy disability and symptom scores used in this study are modifications of those validated elsewhere [1,3,13-16]. A similar system comprising a short symptom assessment and brief clinical examination has proved workable in previous studies of up to 858 patients, correlating well with a standard neurological examination [3].

In this study vibration perception threshold [17], measured using a Biothesiometer was used to compare the clinical scoring systems with a quantitative sensory test of neuropathy, and a high correlation was found. This is in agreement with the findings of Franklin and co-workers [3], who compared their scoring system with the Optacon vibration perception threshold tester and found a similar correlation. The minimum diagnostic criteria employed in this study, moderate signs with or without symptoms, or moderate symptoms with at least mild signs of neuropathy, were chosen to ensure that absent ankle reflexes alone would not be enough to diagnose neuropathy and that symptomatic neuropathy could only be diagnosed if neurological signs were also present, thus avoiding the risk of overestimation by using mild transient symptoms alone [1]. The criteria were also chosen so that the mild symptoms and minor signs of neuropathy that normally occur in the general (non-diabetic) population with increasing age [21] would not distort the possible relationship between diabetic neuropathy and age.

The population surveyed in this study, the largest series reported to date, consisted of diabetic patients attending 
Table 3. Results of logistic regression analysis

\begin{tabular}{lclcl}
\hline Variable & $\begin{array}{l}\text { Parameter } \\
\text { estimate }\end{array}$ & $\begin{array}{l}\text { Standard } \\
\text { error }\end{array}$ & Wald $-\chi^{2}$ & $p$-value \\
\hline Intercept (a) & -4.560 & 0.154 & 872.0 & 0.001 \\
Diabetes type & 0.085 & 0.079 & 1.2 & 0.28 \\
Diabetes duration & 0.044 & 0.003 & 174.1 & 0.001 \\
Age & 0.054 & 0.003 & 436.5 & 0.001 \\
Sex & -0.095 & 0.061 & 2.4 & 0.12 \\
\hline
\end{tabular}

model: $\log (\mathrm{P} / 1-\mathrm{P})=\mathrm{a}+\beta_{1}$ type $+\beta_{2}$ duration $+\beta_{3}$ age $+\beta_{4}$ sex ( $p$, probability of having neuropathy)

routine hospital out-patient diabetes clinics in the UK and the prevalence of $28.5 \%$ may be an overestimate of the prevalence in the population of diabetic patients in general because patients with active complications may be more likely to be attending these clinics.

Franklin et al. [3] stated that the neurological techniques and prevalence of peripheral neuropathy are specific to the population tested. Although the prevalence reported in this study is therefore specific to the UK hospital clinic population, it is similar to that seen in other studies using equivalent methods. In the San Luis Valley study [3] a prevalence of $25.8 \%$ was found in 279 Type 2 diabetic patients whereas $34 \%$ was reported in the 400 patients assessed in the Pittsburgh epidemiology study [6]. This compares with a prevalence of $10.7 \%$ in a study looking at symptomatic neuropathy only, but also applying rigorous criteria, including neurophysiological testing [7], and $14 \%$ in the study of Knuiman et al. [8] which used diminution of pin-prick sensation alone as its diagnostic test.

The equal prevalence of diabetic peripheral neuropathy in both men and women found in this study is in contrast with the male predominance of neuropathy found in both the cross-sectional study of Franklin et al. [3] and Pirart's longitudinal follow-up of 4400 diabetic patients over 26 years [2]. However, in Pirart's study neuropathic symptoms were not used to determine the prevalence of neuropathy and also mononeuropathies were included in the overall prevalence rate. The increasing prevalence of diabetic peripheral neuropathy with duration of diabetes is in keeping with other diabetic population studies which have examined this question $[2,3,6,8]$. The relationship with duration was independent of that with age, which also significantly, and independently, correlated with an increase in the prevalence of diabetic peripheral neuropathy.

Previous studies have either examined all patients irrespective of diabetes type $[1,2,6,8]$ or have concentrated on a specific group, Type 1 diabetic patients [4], Type 2 diabetic patients $[3,5]$ or a specific treatment group [9]. Due to the different methodologies involved it has been difficult to draw conclusions about the prevalence of diabetic neuropathy according to diabetes type. In this study the overall prevalence of diabetic peripheral neuropathy in Type 2 diabetic patients was significantly higher than that in Type 1 diabetic patients. Even after correcting for the Type 2 diabetic patients being older this difference persisted. This trend was maintained throughout the range of known duration of diabetes and may represent the long prodromal period between the onset and diagnosis of Type 2 diabetes [22] or may reflect a true difference in the underlying pathology.

The most important reason for assessing the prevalence of diabetic neuropathy is to assess the risk of neuropathic foot ulceration [23]. When all of the associations, between diabetes type, age and duration are considered, the prevalence of diabetic peripheral neuropathy in Type 2 diabetic patients aged over 60 years and attending the hospital clinic is greater than $50 \%$ and the need for regular examination of the feet, proper footcare and appropriate education for these patients cannot therefore be stressed too often.

Acknowledgements. We would like to thank Wyeth Laboratories for their support of this study and H. Shaikhani and D. Shaw for performing the statistical analysis. We would also like to thank the investigators in every centre for their time and effort in completing the study.

\section{References}

1. Goodman JL, Baumoel S, Frankel L, Marcus LJ, Wasserman S (1953) The diabetic neuropathies. CC Thomas Springfield, Illinois, pp 1-66

2. Pirart J (1979) Diabetes mellitus and its degenerative complications: a prospective study of 4400 patients observed between 1947 and 1973. Diabetes Care 1: 168-188

3. Franklin GM, Kahn LB, Bacter J, Marshall JA, Hamman RF (1990) Sensory neuropathy in non-insulin dependent diabetes mellitus. The San Luis Valley study. Amer J Epidemiol 131: 633643

4. The DCCT Research Group (1988) Factors in the development of diabetic neuropathy. Diabetes 37:476-481

5. Lehtinen JM, Uusitupa M, Siitonen O, Pyörälä K (1989) Prevalence of neuropathy in newly diagnosed NIDDM and nondiabetic control subjects. Diabetes 38: 1307-1313

6. Maser RE, Steenkiste AR, Dorman JS et al. (1989) Epidemiological correlates of diabetic neuropathy: report from Pittsburgh epidemiology of diabetes complications study. Diabetes 38: 1456-1461

7. Boulton AJM, Knight G, Drury J, Ward JD (1985) The prevalence of symptomatic, diabetic neuropathy in an insulin-treated population. Diabetes Care 8: 125-128

8. Knuiman MW, Welborn TA, McCann VJ, Stanton KG, Constable IJ (1986) Prevalence of diabetic complications in relation to risk factors. Diabetes 35: 1332-1339

9. Fry IK, Hardwick C, Scott GW (1962) Diabetic neuropathy: a survey and follow-up of 66 cases. Guys Hosp Rep 111:113-129

10. Newrick PG, Boulton AJM, Ward JD (1986) The distribution of diabetic neuropathy in a British clinic population. Diabetes Res Clin Prac 2: 263-268

11. Neil HAW, Thompson AV, Thorogood M, Fowler GH, Mann JI (1989) Diabetes in the elderly: the Oxford community diabetes study. Diabetic Med 6: 608-613

12. Dyck PJ, Karnes JL, Daube J, O'Brien P, Service FJ (1985) Clinical and neuropathologic criteria for the diagnosis and staging of diabetic polyneuropathy. Brain 108: 861-880

13. Dyck PJ (1988) Detection, characterization and staging of polyneuropathy assessed in diabetics. Muscle Nerve 11: 21-32

14. Melzack R (1984) The McGill pain questionnaire. In: Bromm $P$ (ed) Pain measurement in man. Neurophysiological correlates of pain. Elsevier Scientific Publishers, Amsterdam pp 327-348

15. Masson EA, Gem J, Hunt L, Boulton AJM (1989) A novel approach to the diagnosis and assessment of symptomatic diabetic neuropathy. Pain 38: 25-28

16. Dyck PJ, Kratz KM, Lehman KA et al. (1991) The Rochester diabetic neuropathy study: design, criteria for types of neurop- 
athy, selection bias, and reproducibility of neuropathic tests. Neurology 41: 799-807

17. Steiness IB (1957) Vibratory perception in diabetics. Acta Medica Scand 158: 327-355

18. Bertlesmann FW, Heimans JJ, Weber EJM, van der Veen EA, Schouten JA (1985) Thermal discrimination thresholds in normal subjects and in patients with diabetic neuropathy. $J$ Neurol Neurosurg Psychiatry 48: 685-690

19. Masson EA, Veves A, Fernando D, Boulton AJM (1989) Current perception thresholds: a new, quick and reproducible method for the assessment of peripheral neuropathy in diabetes mellitus. Diabetologia 32: 724-728

20. Consensus Statement (1988) Report and recommendations of the San Antonio conference on diabetic neuropathy. Diabetes 37: 1000-1004

21. Mayne N (1965) Neuropathy in the diabetic and non-diabetic populations. Lancet II: $1313-1316$
22. Jarrett RJ, McCartney P, Keen H (1982) The Bedford survey: ten year mortality rates in newly diagnosed diabetics, borderline diabetics and normoglycaemic controls and risk indices for coronary heart disease in borderline diabetics. Diabetologia 22:7984

23. Boulton AJM (1990) The diabetic foot - neuropathic in origin? RD Lawrence Lecture. Diabetic Med 7: 852-858

Received: 15 May 1992 and in revised form: 12 October 1992

Dr. A.J.M.Boulton

University Dept of Medicine

Manchester Royal Infirmary

Oxford Road

Manchester M13 9WL

UK 